\title{
Effects of super absorbent polymers on soil microbial properties and Chinese cabbage (Brassica chinensis) growth
}

\author{
Xi Li • Ji-Zheng He • Yu-Rong Liu • Yuan-Ming Zheng
}

Received: 21 October 2012 / Accepted: 24 January 2013 /Published online: 7 February 2013

(C) Springer-Verlag Berlin Heidelberg 2013

\begin{abstract}
Purpose New water retention materials, super absorbent polymers (SAPs), have shown the potential to improve some soil physicochemical properties and promote growth of some crop species in arid and semi-arid areas. However, the impacts of SAPs on soil microbial properties are unclear. This study was conducted to clarify the effects of two SAPs on soil microbial properties and Chinese cabbage (Brassica chinensis) growth under different water conditions in the greenhouse.

Materials and methods Experimental conditions included different irrigation conditions and different quantities of SAPs. Chinese cabbage was harvested after 1-month growth in the greenhouse. Meanwhile, soil samples were collected and sieved $\left(<2-\mathrm{mm}\right.$ mesh). Some of the soils were kept at $-4{ }^{\circ} \mathrm{C}$ for analysis of soil physicochemical properties, and some at $-20{ }^{\circ} \mathrm{C}$ for analysis of soil microbial properties. Chinese cabbage samples were thoroughly washed with deionized water for the measurement of fresh weight, shoot length, and root length. Results and discussion The effects from SAPs were not obvious under water sufficient (WC1, watered every 2 days, and $\mathrm{WC} 2$, watered every 4 days) since plant properties were smaller in some SAP treatments than those in control. However, under water deficit (WC3, watered every 8 days), there were significant differences in plant shoot length and
\end{abstract}

Responsible editor: Hailong Wang

X. Li $\cdot$ J.-Z. He $\cdot$ Y.-R. Liu • Y.-M. Zheng $(\bowtie)$

State Key Laboratory of Urban and Regional Ecology, Research

Center for Eco-environmental Sciences, Chinese Academy of

Sciences, Beijing 100085, Peoples Republic of China

e-mail: zhengym@rcees.ac.cn

X. Li

Graduate School, Chinese Academy of Sciences, Beijing 100049,

Peoples Republic of China fresh weight between SAP treatments. There were also significant differences in relative soil water content between water condition (WC) or SAP treatments. The SAPs were beneficial for the formation of large aggregates. Under WC3, the soil organic matter (SOM) increased by 16.9 and $11.5 \%$, soil microbial biomass C (SMBC) by 32.5 and $19.3 \%$, and soil microbial respiration (SMR) by 52.1 and $37.2 \%$ with Jaguar C (JC) and Jaguar S (JS), respectively. Under WC1 and WC2, significantly higher copy numbers of AOA in bulk treatment of JC were found compared with control treatment in this study. Under water deficit, the abundance of bacteria was significantly increased by application of SAPs. For almost every property of soil and plant, JC was showing better effects than JS.

Conclusions Our results showed that cabbage growth was restricted under water-deficit conditions and the application of SAPs could conserve soil water and be useful for increasing cabbage growth under water deficit, improving SOM, SMBC, and SMR under different WC, and stimulating amoA gene AOA copy numbers and bacterial gene copy numbers. Thus, there should be no adverse effects of SAP application on soil microbial environment and Chinese cabbage growth.

Keywords Bacteria $\cdot$ Chinese cabbage $\cdot$ Fungi $\cdot$ Soil microbial biomass carbon - Soil microbial respiration · Super absorbent polymer

\section{Introduction}

Water resource shortage is a critical problem in China, especially in the north area. The north accounts for $64 \%$ of the land area but possesses only $20 \%$ of the water resources of the country (Zhen and Routray 2002). This situation is becoming a major issue restricting agricultural 
development. It is vital to improve the water use efficiency, soil moisture conservation, and water-saving technologies to develop the Chinese agriculture sustainably in the future. New water retention materials, such as super absorbent polymers (SAPs), provide a new way for alleviating water shortage in agricultural production.

SAPs, which are polymers with a super-high capacity for water absorption and water retention, can improve soil waterholding capacity, stabilize soil structure, and thus, increase infiltration and reduce water use, soil nutrient loss, and soil erosion in furrow-irrigated fields (Lentz and Sojka 1994; Lentz et al. 1998). When polymers are incorporated with soil, it is presumed that they retain large quantities of water and nutrients, which are released as required by the plant, so they have been widely applied in agricultural water saving and ecological recovery.

Most studies on SAPs for agriculture have only focused on comparison and evaluation of soil physicochemical properties (Devine and Higginbotham 2005), plant growth (Arbona et al. 2005; Busscher et al. 2009), and the research and progress of new material structure composition and products (Achwal 1997; Liu and Rempel 1997; Li et al. 2004). Research has shown that applications of SAPs can decrease soil water permeability and soil bulk density (Busscher et al. 2009), increase water-holding capacity and the amount of soil water-stable aggregates, and assist in the protection of soil organic matter (Goebel et al. 2005; John et al. 2005). However, the effects of SAPs on the soil ecosystem and the soil microbial ecosystem are not well understood. At the same time, thorough research linking crop physiological characteristics, soil properties, and soil microbial ecology with application of SAPs has not been reported. Soil microorganisms are very active in the interactions with plants and always play important roles in the element cycle of soil nutrients. And thus, soil microbes are being involved with the assessment of soil ecosystem services, such as community structure, abundances (Barrios 2007; Kennedy and Smith 1995). Whether application of SAPs will cause adverse effects or not on the soil ecosystem is therefore an important issue to consider.

The main purpose of this study was to evaluate the effects of SAPs particularly on soil physical properties, Chinese cabbage growth, and soil microorganisms under different water conditions and SAP treatments, which will be helpful to establish a framework for the environmental effect assessment of soil additives in China, also in this research field.

\section{Materials and methods}

\subsection{Materials and growth conditions}

The study was conducted in a greenhouse (temperature, 23.5$24.5{ }^{\circ} \mathrm{C}$; moisture, $32.5-34.5 \%$ ) at the Research Center for Eco-environmental Sciences, Chinese Academy of Sciences, Beijing, P. R. China. Plants received natural light. The soil used in the experiment was cinnamon soil collected from Linfen City, Shanxi Province. Pot cultivation was conducted from August 5 to September 4, 2010. Two SAPs, i.e., Jaguar C (JC) and Jaguar S (JS), extracted from natural plants were selected, and their basic characteristics are given in Table 1.

Plastic pots (height, $18 \mathrm{~cm}$; diameter, $21 \mathrm{~cm}$ ) were filled with $2 \mathrm{~kg}$ air-dried soil with fertilizer application (Table 2). Soil was a loam with organic matter content of $0.8 \%$, pH of 7.6 , and CEC of $13.2 \mathrm{cmol} / \mathrm{kg}$, and classified as Luvisols in Chinese soil taxonomy. The crop was Chinese cabbage (JingYan quality seed).

\subsection{Treatments and soil sampling}

The experimental treatments included control (soil without SAPs), bulk treatment with JC or JS in concentrations of $0.01 \%(w / w)$ by mixing with the soil at $7 \mathrm{~cm}$ in depth. Different watering intervals of 2 (WC1), 4 (WC2), and 8 (WC3) days were employed to examine the effects of the SAPs with different water deficits using $50 \mathrm{~mL}$ water for each watering irrigation. In addition, another treatment with JS sprayed for $4 \mathrm{~s}$ on the soil surface in a concentration of $0.01 \%$ suspension ( $w / V, \mathrm{SAPs} /$ water) was used to compare the effect of different application methods. The watering interval for the surface treatment was every 10 days with $50 \mathrm{~mL}$ water each time.

Soil samples were collected using core samplers after the harvest of Chinese cabbage at the depth of $7 \mathrm{~cm}$. Samples were mixed and sieved ( $<2-\mathrm{mm}$ mesh). Some of the soils were kept at $-4{ }^{\circ} \mathrm{C}$ for analysis of soil physicochemical properties, and some at $-20^{\circ} \mathrm{C}$ for analysis of soil microbial properties.

Table 1 Characteristics of the super absorbent polymers (SAPs)

\begin{tabular}{lllll}
\hline SAP & Manufacturer & Component & $\begin{array}{l}\text { Ingredient } \\
\text { compatibility }\end{array}$ & Particle size (mm) \\
\hline JC & $\begin{array}{c}\text { RHODIA Co., } \\
\text { Ltd }\end{array}$ & $\begin{array}{c}\text { 2-hydroxypropyl 2-hydroxy- } \\
\text { 3-propyl ether }\end{array}$ & Anionic cationic, nonionic, and amphoteric surfactants & $0.05-0.09$ \\
JS & $\begin{array}{c}\text { RHODIA Co., } \\
\text { Physcion-1-glucosylrham- } \\
\text { noside }\end{array}$ & Anionic cationic, nonionic, and amphoteric surfactants & $0.06-0.08$ & Yellow \\
\hline
\end{tabular}


Table 2 Fertilizer application

\begin{tabular}{llll}
\hline Fertilizer type & Fertilizer variety & Fertilizer requirements $(\mathrm{g})$ & Fertilizer use $(\mathrm{g})$ \\
\hline Nitrogen $(\mathrm{N})$ fertilizer & $\mathrm{CO}\left(\mathrm{NH}_{2}\right)_{2}$ & $0.2 \mathrm{~g} / \mathrm{kg}(\mathrm{N})$ & $0.8564 \mathrm{~g} / \mathrm{pot}$ \\
Phosphorus (P) fertilizer & $\mathrm{Ca}\left(\mathrm{H}_{2} \mathrm{PO}_{4}\right)_{2}$ & $0.15 \mathrm{~g} / \mathrm{kg}\left(\mathrm{P}_{2} \mathrm{O}_{5}\right)$ & $0.4944 \mathrm{~g} / \mathrm{pot}$ \\
Potassium (K) fertilizer & $\mathrm{K}_{2} \mathrm{SO}_{4}$ & $0.15 \mathrm{~g} / \mathrm{kg}\left(\mathrm{K}_{2} \mathrm{O}\right)$ & $0.5553 \mathrm{~g} / \mathrm{pot}$ \\
\hline
\end{tabular}

Fertilizers of $\mathrm{P}$ and $\mathrm{K}$ should be applied totally as basal fertilizers at the beginning of experiment. Fertilizer of $\mathrm{N}$ should be applied in three times: basal fertilizer for $50 \%$ of total amount, $30 \%$ fertilizer after thinning, and $20 \%$ fertilizer ten days before harvest

\subsection{Determination of water-stable soil aggregates}

For the determination of water-stable aggregates (WSA), soil samples were gently crushed and passed through an 8$\mathrm{mm}$ sieve. Separation of soil aggregates into different sizes $(<0.25,0.25-0.5,0.5-1,1-2,2-5$, and $>5 \mathrm{~mm})$ was achieved by the wet sieving method of Elliot (1986). Briefly, 100-g sample was immersed in water at room temperature on the largest screen $(2 \mathrm{~mm})$ for $5 \mathrm{~min}$ before sieving commenced. Soils were sieved under water by gently moving the sieve vertically 50 times over a period of 2 min through water contained in a sedimentation cylinder. Recoveries from the wet sieving were $>97 \%$ by weight in all cases. The weight of each WSA fraction was expressed as a proportion of the sum of fraction weights.

\subsection{Soil DNA extraction}

Nucleic acids were extracted from $0.5 \mathrm{~g}$ of fresh soil sample using a MoBio UltraCleanTM soil DNA isolation kit (San Diego, CA, USA) according to the manufacturer's protocol with a minor modification (He et al. 2007). The extracted DNA was stored at $-20{ }^{\circ} \mathrm{C}$ until use.

\subsection{Real-time PCR assay}

Real-time PCR was performed on an iCycler iQ 5 thermocycler (Bio-Rad Laboratories, Hercules, CA, USA). Abundance of archaeal aomA gene was determined in $25 \mu \mathrm{L}$ reaction mixtures containing SYBR ${ }^{\circledR}$ Premix Ex TaqTM (TaKaRa Bio, Otsu, Shiga, Japan) and the primer pairs Arch-amoAF (5'-STAATGGTCTGGCTTAGACG-3') and Arch-amoAR (5'-GCGGCCATCCATCTGTATGT-3') (Francis et al. 2005). Real-time PCR assay was carried out as follows: $2 \mathrm{~min}$ at $94{ }^{\circ} \mathrm{C}$, followed by 40 cycles of $45 \mathrm{~s}$ at $94{ }^{\circ} \mathrm{C}, 1 \mathrm{~min}$ at $53{ }^{\circ} \mathrm{C}, 45 \mathrm{~s}$ at $68{ }^{\circ} \mathrm{C}$, plate read at $83{ }^{\circ} \mathrm{C}$. Abundance of bacterial aomA gene was quantified by Taqman assays in $25 \mu \mathrm{L}$ reaction mixtures containing SYBR ${ }^{\circledR}$ Premix Ex TaqTM (TaKaRa Bio) and the primer pairs amoA1F (5'-GGGGTTTCTACTGGTGGT-3') and amoA2R (5'-CCCCTCKGSAAAGCCTTCTTC-3') (Rotthauwe et al. 1997). The amplification condition was as follows: $5 \mathrm{~min}$ at $95^{\circ} \mathrm{C}$, followed by 35 cycles of $45 \mathrm{~s}$ at
$95{ }^{\circ} \mathrm{C}, 45 \mathrm{~s}$ at $55^{\circ} \mathrm{C}$, and $1 \mathrm{~min}$ at $72{ }^{\circ} \mathrm{C}$. Abundance of fungal $18 \mathrm{~S}$ rRNA gene was determined in $25 \mu \mathrm{L}$ reaction mixtures containing SYBR ${ }^{\circledR}$ Premix Ex TaqTM (TaKaRa Bio) and the primer pairs NS1 (5'-GTAGTCATATGCT TGTCTC-3') and FUNG (5'-ATTCCCCGTTACCCGTTG$3^{\prime}$ ) (May et al. 2001). Real-time PCR assay was carried out as follows: $95^{\circ} \mathrm{C}$ for 3 min followed by 35 cycles of $10 \mathrm{~s}$ at $95^{\circ}$ $\mathrm{C}, 30 \mathrm{~s}$ at $55^{\circ} \mathrm{C}$, and $60 \mathrm{~s}$ at $72{ }^{\circ} \mathrm{C}$, plate read at $83^{\circ} \mathrm{C}$. Abundance of bacterial $16 \mathrm{~S}$ rRNA gene was quantified by Taqman assays in $25 \mu \mathrm{L}$ reaction mixtures containing Probe TM1389F (5'-CTTGTACACACCGCCCGTC-3') and the primer pairs BACT 1369F (5'-CGGTGAATACGTT CYCGG-3') and PROK 1492R (5'-GGWTACCTTGTTA CGACTT-3') (Suzuki et al. 2000). The amplification condition was as follows: $10 \mathrm{~s}$ at $95^{\circ} \mathrm{C}$, followed by 35 cycles of $15 \mathrm{~s}$ at $95^{\circ} \mathrm{C}, 1 \mathrm{~min}$ at $56^{\circ} \mathrm{C}$.

Standard curves for real-time PCR assays were developed as described previously (He et al. 2007). Tenfold serial dilutions of a known copy number of the plasmid DNA were subjected to real-time PCR assay in triplicate to generate an external standard curve as in the previous study (He et al. 2007).

\subsection{Microbial biomass analyses}

Soil microbial biomass was determined using the chloroform fumigation extraction method (Vance et al. 1987). With this technique, in each case, fresh soil was divided into eight portions. Four of these (each containing $10 \mathrm{~g}$ on an oven-dry basis) were placed into $100-\mathrm{mL}$ glass bottles, and chloroform fumigation was performed with the addition of ethanol-free chloroform $(10-\mu \mathrm{L} / \mathrm{g}$ oven-dry soil). The soils were then mixed thoroughly and spread thinly on the inner surface of the bottle. The soils were further fumigated with chloroform for $24 \mathrm{~h}$ at $30^{\circ} \mathrm{C}$ in dessicators. After fumigant removal, the soils were extracted with $40 \mathrm{~mL}$ $0.5 \mathrm{M} \mathrm{K}_{2} \mathrm{SO}_{4}$ for $30 \mathrm{~min}$. The other four replicates of each non-fumigated soil were extracted similarly at the onset of fumigation. Microbial $\mathrm{C}$ was estimated as the difference in $\mathrm{K}_{2} \mathrm{SO}_{4}$-extractable dissolved organic carbon between fumigated and unfumigated soils using as extractability correction factor: $K_{\mathrm{C}}=0.45$ for C (Jonasson et al. 1996; Rinnan et al. 2008). The amount of soluble $C$ was that extracted from 
non-fumigated soil. The soil extracts were frozen until their $\mathrm{C}$ content was measured. The $\mathrm{C}$ in the fumigated and unfumigated soil extracts was determined using a Total Dissolved Organic Carbon Analyzer (TOC-Vesh).

\subsection{Soil respiration}

Soil respiration was measured using the method described by Chen et al. (2000). Field moist subsamples (20 g dry weight equivalent) were placed in sealed $500-\mathrm{mL}$ glass bottles and aerobically incubated at $22{ }^{\circ} \mathrm{C}$ and at constant humidity in an incubator. Carbon dioxide derived from the soil was trapped in $0.1 \mathrm{M} \mathrm{NaOH}$ and measured after $24 \mathrm{~h}$ by titration with $0.1 \mathrm{M}$ $\mathrm{HCl}$ to the phenolphthalein end point after the addition of $1 \mathrm{M}$ $\mathrm{BaCl}_{2}$. A number of controls (i.e., glass bottles without soil) were subjected to the same conditions and used as blanks. The amount of carbon dioxide derived was calculated from the difference in molarity between the $\mathrm{NaOH}$ from blanks and samples.

\subsection{Data processing and statistical analysis}

Statistical analysis was performed using SPSS software version 17.0 (SPSS Inc., Chicago, IL, USA). Multivariate analysis of variance followed by LSD and S-N-K test was used to check the differences between treatments, and Pearson's correlation was used to check the relationship among soil organic matter, soil microbial biomass carbon, and soil microbial respiration. Results are presented as means of four replicates per treatment \pm standard error of the mean. $P<0.05$ was considered to be statistically significant.

\section{Results}

\subsection{Plant properties}

Water condition (WC) exerted significant differences on the Chinese cabbage shoot length, root length, or fresh weight (Fig. 1), indicating the important role of water during the plant growth. The effects from super absorbent polymers (SAPs) were not obvious when water is sufficient since plant properties were smaller in some SAP treatments than those in control. However, under water deficit (only watered every 8 days), the SAPs increased plant shoot length significantly by $17.8 \%$ (JC) and $16.6 \%$ (JS), and fresh weight significantly by $42.0 \%$ (JC) and $78.6 \%$ (JS).

\subsection{Soil water content}

There were significant differences in relative soil water content between WC or SAP treatments (Fig. 2). The JC and JS increased the soil water content by 21.9 and $32.5 \%$ with
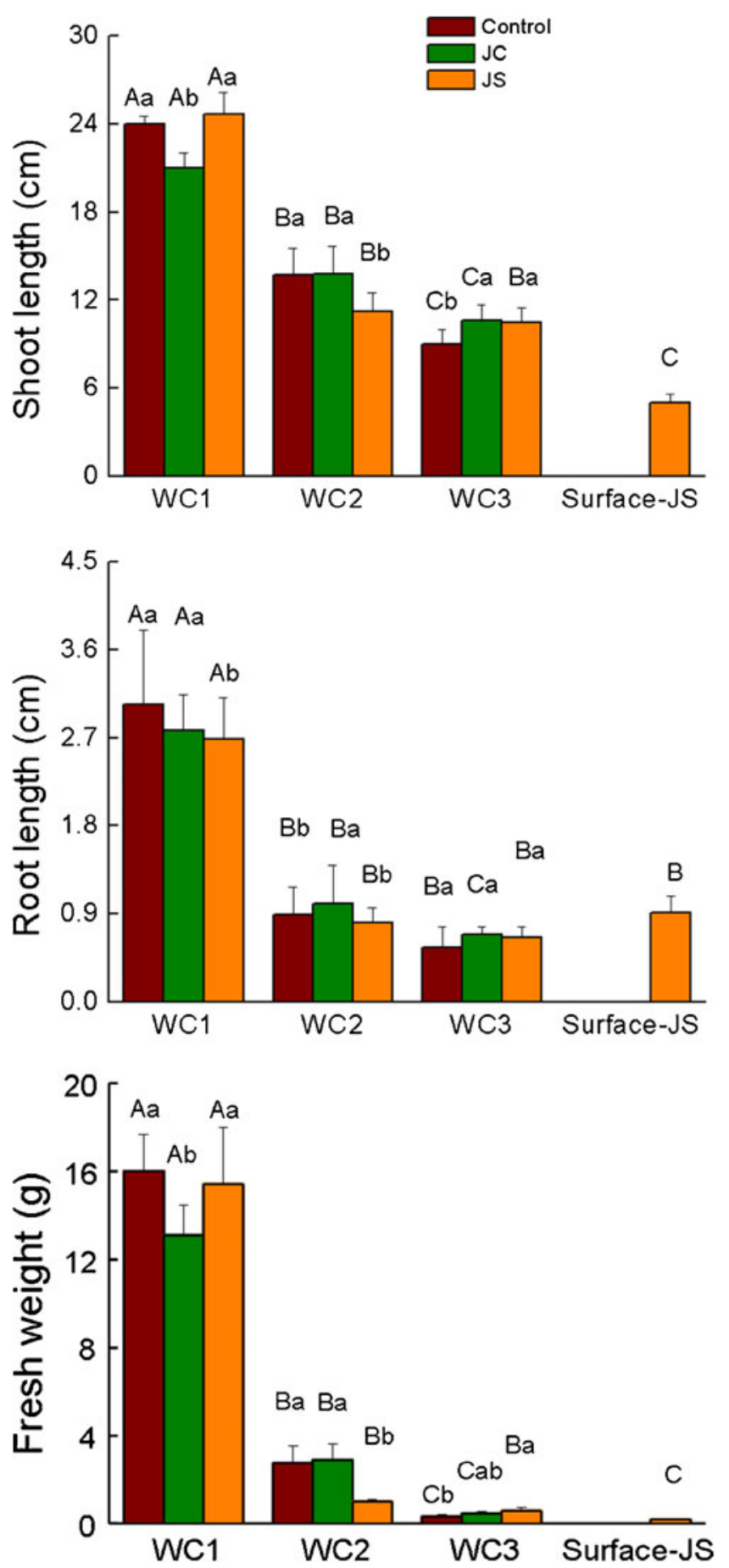

Fig. 1 Plant shoot length, root length, and fresh weight in Chinese cabbage plant under different water condition (WC) and SAP treatments. Capital letters indicate the significant differences between WC treatments in the same SAP treatment $(P<0.05)$. Lowercase letters indicate the significant differences between SAP treatments in the same WC treatment $(P<0.05)$. Small bars show standard errors

watering intervals at 2 days, 25 and $11.1 \%$ with watering intervals at 4 days, and 18.2 and $11.4 \%$ with watering intervals at 8 days, respectively, compared with control. Nevertheless, retention of water in the JC treatment was nearly 


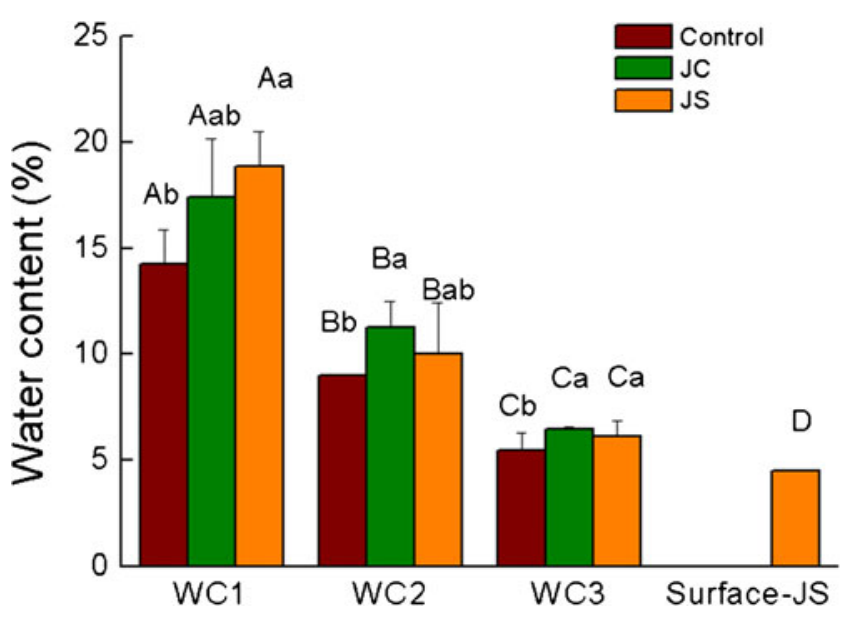

Fig. 2 Soil water content under different WC and SAP treatments. Capital letters indicate the significant differences between WC treatments in the same SAP treatment $(P<0.05)$. Lowercase letters indicate the significant differences between SAP treatments in the same WC treatment $(P<0.05)$. Small bars show standard errors

no difference with that in the JS treatment under every WC. As time between watering increased, soil water content showed the declining trend. Under water deficit, water content in the surface treatment of JS was less than that in the bulk treatment of JS.

\subsection{Soil water-stable aggregates}

Adding SAPs into soil significantly altered soil water-stable aggregates (Table 3). Compared with control, SAPs made the soil aggregates distributed more evenly, which meant that the aggregates with small size $(<0.25 \mathrm{~mm})$ decreased while those with big size increased accordingly. All of the SAP treatments significantly increased the soil aggregates with size $>0.25$,
$>0.5$, and $>1 \mathrm{~mm}$. There were no significant differences in soil particle sizes between SAP treatments under different WC.

\subsection{Soil organic matter}

There were significant differences in soil organic matter (SOM) between SAP or different WC treatments (Fig. 3). In comparison with the control, the JC and JS increased the SOM significantly in all of the treatments. Meanwhile, effects of the JC were much greater than those of the JS. As time between watering increased, similar to water content, values of SOM also showed the declining trend. Under water deficit, SOM in the surface treatment of JS was less than in the bulk treatment of JS.

\subsection{Microbial biomass $\mathrm{C}$ and soil microbial respiration}

Soil microbial biomass C (SMBC) and soil microbial respiration (SMR) differed significantly between SAP or WC treatments (Fig. 4). In all of the WC treatments characterizing with SMBC and SMR, SAPs were stimulating the microbial activities with the following order: JC $>$ JS $>$ control. Under water deficit, SMBC and SMR in the surface treatment of JS were higher than in the bulk treatment of JS.

\subsection{Abundance of AOA, AOB, bacteria, and fungi} in the soil

Archaeal amoA gene copy numbers showed a decreasing trend as intervals between watering increased only in the JC treatment (Fig. 5), which contained the highest archaeal amoA gene copy numbers, $2.37 \times 10^{7}$ copies per gram of dry soil, with watering every 2 days. Meanwhile, JC significantly improved the AOA abundances at $\mathrm{WC} 1$ and $\mathrm{WC} 2$

Table 3 Soil water-stable aggregate composition under different WC and SAP treatments

\begin{tabular}{|c|c|c|c|c|c|c|c|c|c|}
\hline \multirow[t]{2}{*}{ Method of application } & \multicolumn{6}{|c|}{ The amounts of soil water-stable aggregates (\%) } & \multicolumn{3}{|l|}{ Subtotal } \\
\hline & $<0.25 \mathrm{~mm}$ & $0.25-0.5 \mathrm{~mm}$ & $0.5-1 \mathrm{~mm}$ & $1-2 \mathrm{~mm}$ & $2-5 \mathrm{~mm}$ & $>5 \mathrm{~mm}$ & $>0.25 \mathrm{~mm}$ & $>0.5 \mathrm{~mm}$ & $>1 \mathrm{~mm}$ \\
\hline C-WC1 & $45.2 \mathrm{Aa}$ & $17.1 \mathrm{Ab}$ & $11.4 \mathrm{Ab}$ & $7.8 \mathrm{Ab}$ & $8.9 \mathrm{Aa}$ & $9.7 \mathrm{Ab}$ & $54.8 \mathrm{Ab}$ & $37.8 \mathrm{Ab}$ & $26.4 \mathrm{Ab}$ \\
\hline JC-WC1 & $26.4 \mathrm{Ab}$ & $21.8 \mathrm{Aa}$ & $20.6 \mathrm{Aa}$ & $10.6 \mathrm{Aa}$ & $9.3 \mathrm{Aa}$ & $11.3 \mathrm{Aa}$ & $73.6 \mathrm{Aa}$ & $51.8 \mathrm{Aa}$ & $31.2 \mathrm{Aa}$ \\
\hline JS-WC1 & $27.9 \mathrm{Ab}$ & $21.8 \mathrm{Aa}$ & $20.3 \mathrm{Aa}$ & $10.2 \mathrm{Aa}$ & $9.1 \mathrm{Aa}$ & $10.8 \mathrm{Aa}$ & $72.1 \mathrm{Aa}$ & $50.3 \mathrm{Aa}$ & $30.0 \mathrm{Aa}$ \\
\hline C-WC2 & $44.0 \mathrm{Aa}$ & $17.9 \mathrm{Ab}$ & $11.1 \mathrm{Ab}$ & 7.9 Ab & $8.9 \mathrm{Aa}$ & $10.3 \mathrm{Aa}$ & $56.1 \mathrm{Ab}$ & $38.1 \mathrm{Ab}$ & $27.1 \mathrm{Ab}$ \\
\hline JC-WC2 & $26.9 \mathrm{Ab}$ & $22.1 \mathrm{Aa}$ & $20.4 \mathrm{Aa}$ & $10.8 \mathrm{Aa}$ & $9.2 \mathrm{Aa}$ & $10.7 \mathrm{Aa}$ & $73.1 \mathrm{Aa}$ & $51.0 \mathrm{Aa}$ & $30.6 \mathrm{Aa}$ \\
\hline JS-WC2 & $27.5 \mathrm{Ab}$ & $22.3 \mathrm{Aa}$ & $20.1 \mathrm{Aa}$ & $10.3 \mathrm{Aa}$ & $9.1 \mathrm{Aa}$ & $10.6 \mathrm{Aa}$ & $72.5 \mathrm{Aa}$ & $50.2 \mathrm{Aa}$ & $30.1 \mathrm{Aa}$ \\
\hline C-WC3 & $41.5 \mathrm{Aa}$ & $21.4 \mathrm{Ab}$ & $10.1 \mathrm{Ab}$ & $7.8 \mathrm{Ab}$ & $9.0 \mathrm{Aa}$ & $10.2 \mathrm{Ab}$ & $58.5 \mathrm{Ab}$ & $37.1 \mathrm{Ab}$ & $27.0 \mathrm{Ab}$ \\
\hline JC-WC3 & $26.7 \mathrm{Ab}$ & $21.6 \mathrm{Aa}$ & $20.1 \mathrm{Aa}$ & $11.4 \mathrm{Ba}$ & $9.1 \mathrm{Aa}$ & $11.1 \mathrm{Aa}$ & $73.3 \mathrm{Aa}$ & $51.7 \mathrm{Aa}$ & $31.6 \mathrm{Aa}$ \\
\hline JS-WC3 & $27.9 \mathrm{Ab}$ & $21.9 \mathrm{Aa}$ & $19.6 \mathrm{Aa}$ & $10.8 \mathrm{Aa}$ & $9.0 \mathrm{Aa}$ & $10.6 \mathrm{Ab}$ & $71.8 \mathrm{Aa}$ & $49.9 \mathrm{Aa}$ & $30.3 \mathrm{Aa}$ \\
\hline Surface-JS & $27.5 \mathrm{Ab}$ & $22.7 \mathrm{Aa}$ & $19.9 \mathrm{Aa}$ & $10.5 \mathrm{Aa}$ & $9.0 \mathrm{Aa}$ & $10.4 \mathrm{Ab}$ & $72.6 \mathrm{Aa}$ & $49.9 \mathrm{Aa}$ & $29.9 \mathrm{Aa}$ \\
\hline
\end{tabular}

Different capital letters indicate significant differences between WC treatments in the same SAPs treatment $(P<0.05)$.Different lowercase letters indicate differences among the SAP treatments in the same WC treatment $(P<0.05)$ 


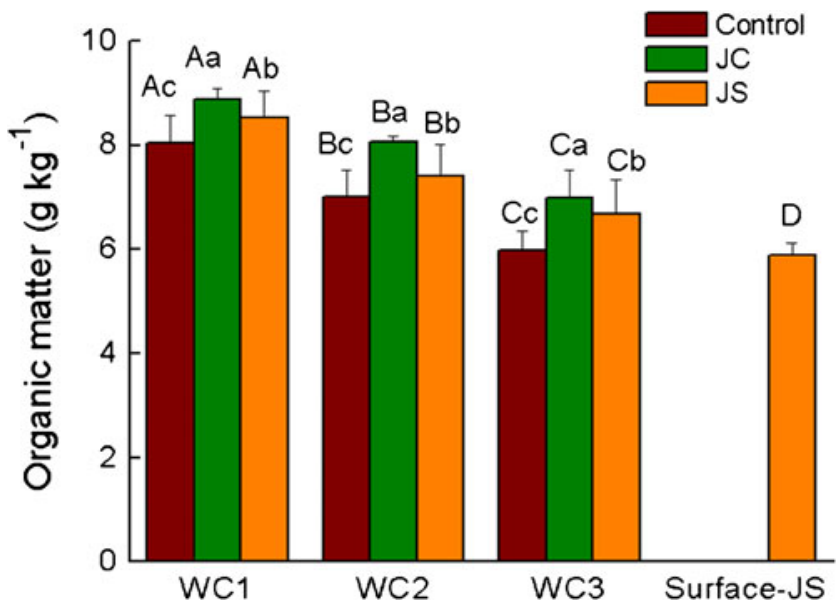

Fig. 3 Organic matter under different WC and SAP treatments. Capital letters indicate the significant differences between WC treatments in the same SAP treatment $(P<0.05)$. Lowercase letters indicate the significant differences between SAP treatments in the same WC treatment $(P<0.05)$. Small bars show standard errors

compared with control and JS, while there were no significant differences at WC3. In contrast to the abundance of AOA, there were no significant differences in the bacterial amoA gene copy numbers among different treatments (see Fig. 5). The bacterial amo $A$ gene copy numbers in different treatments, ranging from 0.40 to $1.79 \times 10^{8}$ per gram of dry soil, were much higher than those of archaeal amoA gene copy numbers.

The real-time PCR assays, targeting the bacterial $16 \mathrm{~S}$ rRNA gene, yielded $2-3 \times 10^{9}$ copies per gram of dry soil in different treatments (see Fig. 5). There were no significant differences in the bacterial $16 \mathrm{~S}$ rRNA gene copy numbers between different SAPs and WC treatments except WC3.

The fungal $18 \mathrm{~S}$ rRNA genes were $1.27-3.69 \times 10^{7}$ copies per gram of dry soil in different treatments (see Fig. 5). There were significant differences in the fungal $18 \mathrm{~S}$ rRNA gene copy numbers between SAP treatments at WC1. Under water deficit (WC3 and surface-JS), fungal $18 \mathrm{~S}$ rRNA gene copy numbers of the surface-JS were higher than those of bulk treatments of JC and JS, respectively.

\section{Discussion}

\subsection{Effect of SAPs on the growth of Chinese cabbage}

Our results indicate that applications of SAPs had a remarkable effect on Chinese cabbage shoot length in WC3, which water supply was limited, but there were almost no significant differences in Chinese cabbage root length or fresh weight between the SAPs treatments in WC1 and WC2. Previous research under both field and laboratory conditions has shown similar results (Yazdani et al. 2007; Islam et al. 2011). Under sufficient water supply, SAPs from plant extracts were not beneficial to the growth of Chinese cabbage. This was the same with SAPs from synthetic polymeric materials, whose effects were less noticeable under adequate and moderate irrigation (Islam et al. 2011). SAPs from plant extracts can improve cabbage growth under water deficit. Therefore, there should be no adverse effects of SAP application on Chinese cabbage growth.

\subsection{Effect of SAPs on soil water content and soil water-stable aggregates}

SAPs had significant effects on soil water content and soil water-stable aggregates. The water retention capacities of soils were increased as a result of the addition of SAPs under different WC or SAP treatments, with the greatest influence resulting from the treatments in WC1. Applications of SAPs could conserve different amounts of water in themselves,
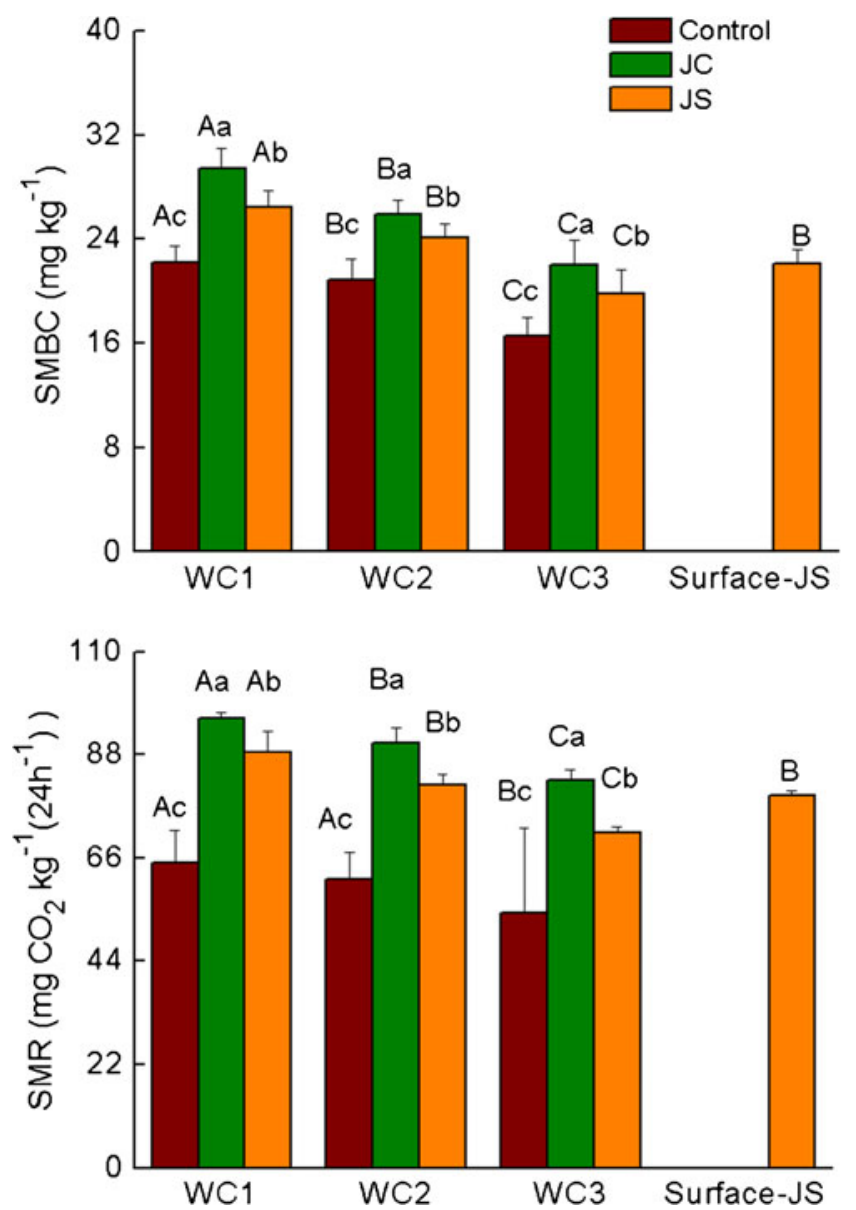

Fig. 4 Soil microbial biomass carbon (SMBC) and soil microbial respiration (SMR) under different WC and SAP treatments. Capital letters indicate the significant differences between WC treatments in the same SAP treatment $(P<0.05)$. Lowercase letters indicate the significant differences between SAP treatments in the same WC treatment $(P<0.05)$. Small bars show standard errors 

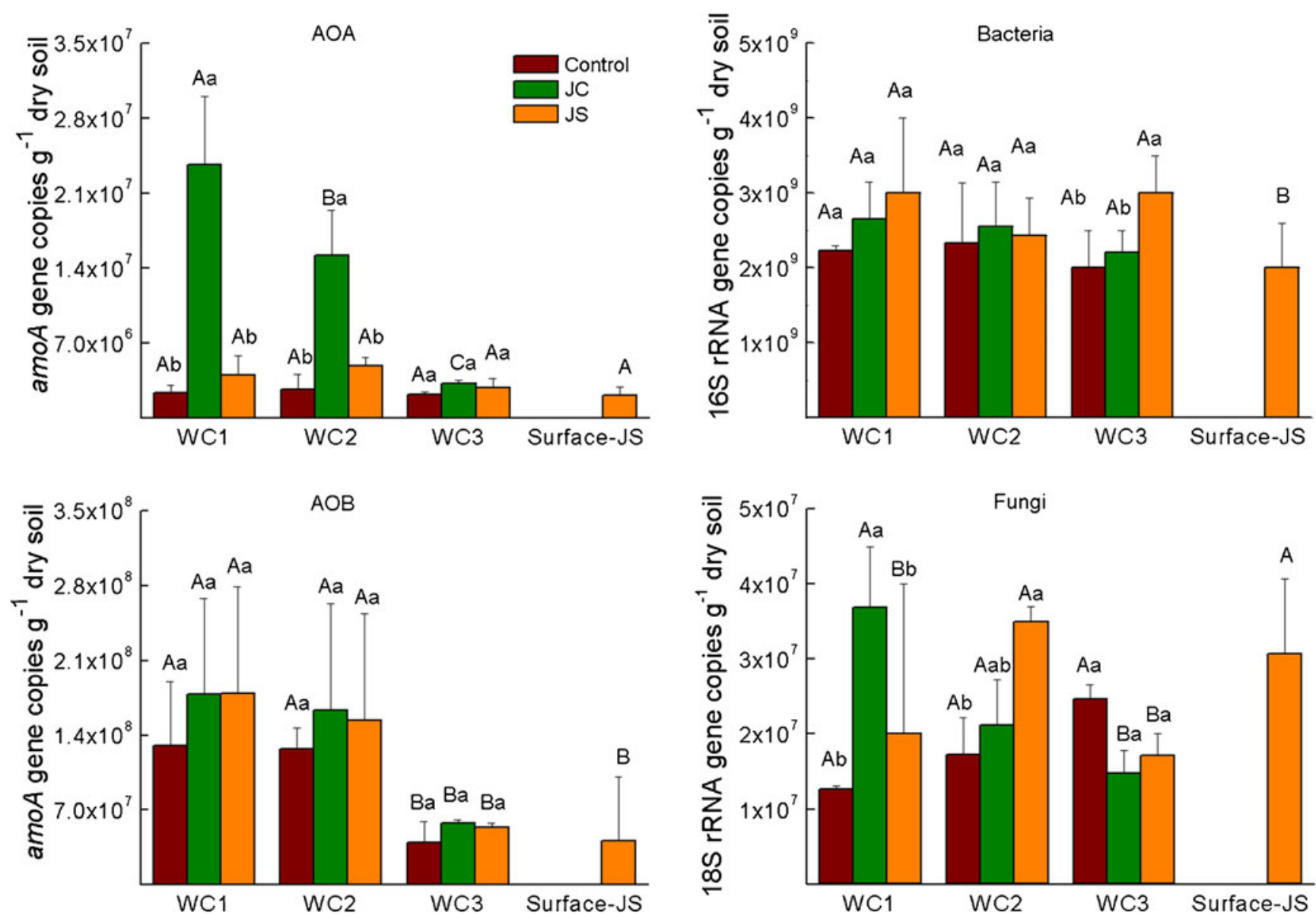

Fig. 5 Abundance of AOB, AOA, bacteria, and fungi under different $\mathrm{WC}$ and SAP treatments. Capital letters indicate the significant differences between WC treatments in the same SAP treatment $(P<0.05)$.

thereby increasing the soil capacity for water storage, ensuring more available water potentially. Application of SAPs could be an effective management practice for cabbage cultivation in soils characterized by low water-holding capacity leading to poor water and fertilizer use efficiency by crops (Karimi et al. 2009).

Our data have shown remarkable effects on soil aggregates by SAPs. SAPs increased the percentage of large aggregates. SAPs may allow soil cementation to form aggregates, especially $>1-\mathrm{mm}$ aggregates. This should be due to the increase of SOM by adding SAPs. High SOM can bind soil particles together into aggregates, which are essential in improving soil structure (Handreck and Black 2002) since the large aggregates can effectively stabilize soil structure, modify the soil permeability, prevent soil crusts, and reduce soil evaporation.

\subsection{Effect of SAPs on SOM, SMBC, and SMR}

Our results have shown that soil organic matter was increased by adding SAPs and the effects of JC were greater than those

Lowercase letters indicate the significant differences between SAP treatments in the same WC treatment $(P<0.05)$. Small bars show standard error

of JS. The maintenance of the SOM carbon concentration has been suggested to be a consequence of biomass production during plant growth (de la Rosa and Knicker 2011). Meanwhile, SAPs had the potential benefit of helping retain SOM in the soil by incorporating it into aggregates where it can be protected from decomposition (Goebel et al. 2005; John et al. 2005). However, increase in SOM did not improve cabbage growth in the sufficient water regime, only in the water deficit treatment.

In our study, SOM, SMBC, and SMR were observed to be higher after adding SAPs, and we found that SOM was related to SMBC and SMR (significant positive correlation, $P<0.05)$ via analysis of Pearson's correlation. Both aboveground and belowground factors might affect microbial biomass and, therefore, nutrient availability (García et al. 2002; Schade and Hobbie 2005). In this study, soil chemical and physical characteristics, like SOM and soil structure and texture, may also constrain microbial growth (Hassink 1994), and then, the variability of these properties along the soil profile can be reflected in microbial communities (Fierer et al. 2003). Our result had demonstrated the 
stimulating effects of SOM on microbial growth, which might be related to the direct effects of SAPs and the indirect effects from SOM. Consequently, SAPs could affect soil microbial function and thus, the ecosystem geochemical process. This could indicate that SAPs might improve microbial dynamics.

4.4 Effect of SAPs on abundance of AOA, AOB, bacteria, and fungi in soil

Significantly higher copy numbers of AOA in the bulk treatments of JC under WC1 and WC2 were found compared with control and JS, indicating JC could be a stimulative factor for AOA community in the soil. Some studies had given the indications that AOA in arable soil might be stimulated by the increase of organic matter (Schauss et al. 2009; Valentine 2007). In this study, SAPs increased the SOM, and then, SAP could indirectly improve abundance of AOA.

No significant differences in AOB abundance were observed among the different treatments, suggesting that SAP input was not a substantial factor for the AOB community in the soil. Bacteria can grow in high-fertility soils, whereas archaea may gain the competitive advantage in conditions of energy stress, for example, in low-fertility soils (Di et al. 2009). Soils in the north of China were in low-fertility. Effects of SAPs on the soil fertility might not be obvious enough in stimulating the growth of AOB.

This study demonstrated the differences in copy numbers of bacterial $16 \mathrm{~S}$ rRNA genes between the SAP treatments and control under water deficit (WC3). Our data also showed a higher abundance of fungi after adding SAPs under WC1 and WC2. Also, the abundance of fungi in surface JS was significantly higher than that of WC1 and WC3 treatments, which might be related to the application method of JS. Probably, surface treatment of JS was more beneficial to the soil fungi than bulk treatment. Anyway, this obviously different trend of fungi with other microbial properties should be paid more attention in the future study. Thus, at least, there should be no adverse effects of SAP application on soil microbial environment.

Although application of SAPs in different WC was beneficial to soil physical properties and soil microbial activities, the effects of SAPs on soil water, which is actually available to plants, are still unclear. Soil moisture composition needs to be further investigated to verify the mechanisms of SAPs on the soil water and plant growth.

\section{Conclusions}

Our results based on a greenhouse experiment of Chinese cabbage supported that the use of SAPs would improve the soil physical properties, which might assist the control of water loss, and improve some soil microbial activities. Our results showed that cabbage growth was restricted under water deficit and the application of SAPs could conserve soil water, which was useful for increasing cabbage growth, stimulating bacterial gene copy numbers, improving large soil aggregates, SOM, SMBC, and SMR under different WC, and stimulating amoA gene AOA copy numbers. For almost every property of soil and plant, JC was showing better effects than JS. Totally, SAPs caused no adverse effects on soil microbial environment and Chinese cabbage growth.

Acknowledgments This study was supported by the National Science Foundation of China $(41025004,41071163)$ and the Youth Innovation Promotion Association, Chinese Academy of Sciences.

\section{References}

Achwal WB (1997) Optimum conditions for microbial degradation of poly (vinylalcohol) in wastewater. Colourage 44:47-48

Arbona V, Iglesias DJ, Jacas J, Primo-Millo E, Talon M, GamezCadenas A (2005) Hydrogel substrate amendment alleviates drought effects on young citrus plants. Plant Soil 270:73-82

Barrios E (2007) Soil biota, ecosystem services and land productivity. Ecol Econ 64:269-285

Busscher WJ, Bjorneberg DL, Sojka RE (2009) Field application of PAM as an amendment in deep-tilled US southeastern coastal plain soils. Soil Till Res 104:215-220

Chen C, Condron LM, Davis M, Sherlock RR (2000) Effects of afforestation on phosphorus dynamics and biological properties in a New Zealand grassland soil. Plant Soil 220:151-163

Devine DM, Higginbotham CL (2005) Synthesis and characterization of chemically crosslinked N-vinyl pyrrolidione (NVP) based hydrogels. Eur Polym J 41:1272-1279

de la Rosa JM, Knicker H (2011) Bioavailability of N released from Nrich pyrogenic organic matter: an incubation study. Soil Biol Biochem 43:2368-2373

Di HJ, Cameron KC, Shen JP, Winefield CS, Callaghan MO, Bowatte $\mathrm{S}$, He JZ (2009) Nitrification driven by bacteria and not archaea in nitrogen-rich grassland soils. Nat Geosci 10:1-4

Elliot ET (1986) Aggregate structure and carbon, nitrogen, and phosphorus in native and cultivated soils. Soil Sci Soc Am J 50:627-633

Fierer N, Schimel JP, Holden PA (2003) Variations in microbial community composition through two soil depth profiles. Soil Biol Biochem 35:167-176

Francis CA, Roberts KJ, Beman JM, Santoro AE, Oakley BB (2005) Ubiquity and diversity of ammonia oxidizing archaea in water columns and sediments of the ocean. Proc Natl Acad Sci USA 102:14683-14688

García C, Hernandez T, Roldan A, Martin A (2002) Effect of plant cover decline on chemical and microbiological parameters under Mediterranean climate. Soil Biol Biochem 34:635-642

Goebel MO, Bachmann J, Woche SK, Fischer WR (2005) Soil wettability, aggregate stability, and the decomposition of soil organic matter. Geoderma 128:80-93

Handreck KA, Black ND (2002) Growing media for ornamental plants and turf (3rd ed). University of New South Wales Press, Sydney, pp 498-501

Hassink J (1994) Effect of soil texture on the size of the microbial biomass and on the amount of $\mathrm{C}$ and $\mathrm{N}$ mineralized per unit of microbial biomass in Dutch grassland soils. Soil Biol Biochem 26:1573-1581 
He JZ, Shen JP, Zhang LM, Zhu YG, Zheng YM, Xu MG, Di HJ (2007) Quantitative analyses of the abundance and composition of ammonia-oxidizing bacteria and ammonia-oxidizing archaea of a Chinese upland red soil under long-term fertilization practices. Environ Microbiol 9:2364-2374

Islam MR, Hu Y, Mao S, Jia P, Eneji AE, Xue X (2011) Effects of water-saving superabsorbent polymer on antioxidant enzyme activities and lipid peroxidation in corn (Zea mays L.) under drought stress. J Sci Food Agric 91:813-819

Jonasson S, Michelsen A, Schmidt IK, Nielsen EV (1996) Microbial biomass $\mathrm{C}, \mathrm{N}$ and $\mathrm{P}$ in two arctic soils and responses to addition of NPK fertilizer and sugar: implications for plant nutrient uptake. Oecologia 106:507-515

John B, Yamashita T, Ludwig B, Flessa H (2005) Storage of organic carbon in aggregate and density fractions of silty soils under different types of land use. Geoderma 128:63-79

Karimi A, Noshadi M, Ahmadzadeh M (2009) Effects of super absorbent polymer (igeta) on crop, soil water and irrigation interval. J Sci Technol Agric Nat Res 12:415-420

Kennedy AC, Smith KL (1995) Soil microbial diversity and the sustainability of agricultural soils. Plant Soil 170:75-86

Lentz RD, Sojka RE (1994) Field result using polyacrylamide to manage furrow erosion and infiltration. Soil Sci 158:274-282

Lentz RD, Sojka RE, Robbins CW (1998) Reducing phosphorus losses from surface-irrigated fields: emerging polyacrylamide technology. J Environ Qual 27:305-312

Li YF, Li XZ, Zhou LC, Zhu XX, Li BN (2004) Study on the synthesis and application of salt-resisting polymer hydrogels. Polym Advan Technol 15:34-38

Liu IS, Rempel GL (1997) Effect of organic solvents on the synthesis of super absorbents. J Appl Polym Sci 64:1345-1351
May LA, Smiley B, Schmidt MG (2001) Comparative denaturing gradient gel electrophoresis analysis of fungal communities associated with whole plant corn silage. Can J Microbiol 47:829-841

Rinnan R, Michelsen A, Jonasson S (2008) Effects of litter addition and warming on soil carbon, nutrient pools and microbial communities in a subarctic heath ecosystem. Appl Soil Ecol 39:271-281

Rotthauwe JH, Witzel KP, and Liesack W (1997) The ammonia monooxygenase structural gene amoA as a functional marker: molecular fine-scale analysis of natural ammonia-oxidizing populations. Appl Environ Microbiol 63:4704-4712

Schade JD, Hobbie SE (2005) Spatial and temporal variation in islands of fertility in the Sonoran Desert. Biogeochemistry 73:541-553

Schauss K et al (2009) Dynamics of functional relevance of ammoniaoxidizing archaea in two agricultural soils. Environ Microbiol 11:446-456

Suzuki MT, Taylor LT, DeLong EF (2000) Quantitative analysis of small-subunit rRNA genes in mixed microbial populations via 5'nuclease assays. Appl Environ Microbiol 66:4605-4614

Vance ED, Brookes PC, Jenkinson DS (1987) An extraction method for measuring microbial biomass C. Soil Biol Biochem 22:703707

Valentine DL (2007) Adaptations to energy stress dictate the ecology and evolution of the Archaea. Nature Rev Microbiol 5:316-323

Yazdani F, Allahdadi I, Akbari GA (2007) Impact of superabsorbent polymer on yield and growth analysis of soybean (Glycine max L.) under drought stress condition. Pakistan J Biol Sci 10:4190-4196

Zhen L, Routray JK (2002) Groundwater resource use practices and implications for sustainable agricultural development in the north China plain: a case study in Ningjin County of Shandong Province, PR China. Int J Water Resour D 18(4):581-593 